such as macromolecules, chemical mechanisms determining drug activity, physico-chemical considerations, the modification of drugs by living organisms, and the effect of specific chemical groups; and the second part, consisting of sixteen chapters, covers a wide range of selected topics, such as growth factors and their antagonists (five chapters), porphyrins, choline and its derivatives, quinones, symbiosis and parasitism, antibiotics, some aspects of hormones, chemotherapeutic agents and insecticides (three chapters), cancer, plant growth regulators, and immunology. While many of these topics could, as some have already done, form the subjects of lengthy monographs, the author has attempted to embrace them all in a volume of less than four hundred text pages. The effect is that some of the chapters are admirable short surveys which do justice to the subject-matter, whereas others are too briefly kaleidoscopic. To compensate for the inevitable compression, Dr. Sexton has made good use of tables, nearly sixty in all, for the concise presentation of data; and at the end of each chapter he has given excellent lists of leading references, these, in themselves a mine of information, being a most valuable feature of the work.

The two chapters dealing with pyridoxin, pantothenic acid, biotin, pyrimidines, purines, and pterins are excellent reviews, but it is indicative of the rate of progress that folic acid antagonists are scarcely mentioned. The chapter on plant growth regulators, to which Dr. Sexton's own researches have contributed notably, is a valuable review of a widely scattered literature, but the oat coleoptile test might have been described with greater accuracy.

Although written in a very readable manner, the work is marred by a considerable number of errors that should not have appeared in a book, which is not really a long one, costing as much as this one does. In the table of natural $\alpha$-amino-acids, which is "given for reference purposes", the formulæ for thyroxine and threonine are given wrongly. These are not the only erroneous structural formulæ, which is to be regretted since a book of this kind giving a wealth of structural formulæ for many substances of topical interest is likely to be used for reference purposes in such matters. The following are given incorrect structural formulæ: eserine, tubocurarine, myanesin, endochin, benzoylglycuronic acid, phenylglycuronic acid, polyglutamic acid, and poly-N. acetylglucosamine, while the chemistry given for muscarine, formulated as the aldehyde corresponding to $\operatorname{cholin} \theta$, was discredited many years ago. There is evidence also of lack of care in the rendering of scientific terms : thus, strepogenin appears repeatedly as streptogenin, and adrenochrome as adenochrome; dibromosalicil appears as dibromosalicin, quite another matter, and the anthrax bacillus appears twice as Bacillus anthris and once, correctly, as Bacillus anthracis; $P$. cathemerium appears as $P$. catherrarium, and a table of covalent radii is given under the heading of bond-lengths. Although the Chemical Society had misgivings about the term 'radicle' in 1905 and took another twenty years to replace it by 'radical', the obsolete rendering is consistently used in this book. The unfortunate impressions are given that riboflavin, rather than mepacrine, has antibacterial and antimalarial properties (p. 93), that aspirin will protect animals against the physiological effects of administered thyroglobulin or thyroxine (p. 387), and that the antiserum to a synthetic antigen derived from cellobiuronic acid, while precipitating the capsular polysaccharide of pneumococcus type III when the latter was combined with a heterologous protein, also "precipitated antisera to pneumococei types II, III and VIII" (p. 385).

The timeliness of a book of this nature will be readily conceded; but it is to be regretted that a much-needed volume should contain numerous minor inaccuracies. Apart from the somewhat inelegant rendering of the porphyrin structural formulæ, the standard of printing is high, and the volume is attractively bound.

J. WALKER

\section{VISUAL AIDS IN SCIENCE TEACHING}

Visual Aids

Their Construction and Use. By Gilbert G. Weaver and Prof. Elroy W. Bollinger. Pp. vii +388 . New York: D. Van Nostrand Co., Ine.; London : Macmillan and Co., Ltd., 1949.) 36s. net.

THIS book is superior in most respects to the large and well-bound volumes on visual aids to teaching, particularly to the teaching of technology, which appear at fairly frequent intervals in the United States. At the price of $36 s$. it must be regarded as expensive for a work of less than four hundred pages, many of which only deal with the problem from the American point of view.

The really useful part of the book discusses in a thorough though sometimes rather obvious manner the older direct and the newer optical projection methods of presenting material to students of the commoner technologies. Strangely, the authors seem to handle the methods which employ blackboards, display cases, posters and pictures with more conviction than they evince with the cinema and other optical devices. Perhaps this is all to the good, for the glamour of elaborate optical aids has tended to obscure their real purpose : they should be regarded as useful teaching tools and nothing more.

One of the main shorteomings in works of this kind is that they fail to stress sufficiently that the film, picture, model or diagram is in itself no cure for verbalism, even though each is thoroughly understood so far as its spatial, colour and temporal relationships are concerned. In the work under review, some space has been devoted to this important matter. The plain fact is that the scientific worker and technologist, in common with others, need languages to express their ideas and as vehicles of creative thought. It is necessary to spot the most convenient languages for the task in hand, whether these are verbal, symbolical or pictorial. This is true of both the research worker and the teacher. Further, there must be facility in translating from one language to another, and this is exactly where there is a failure to meet the needs of basic thought and teaching in science. The cure for verbalism is not the equally vicious complaint of pictorialism nor, in extreme cases, eidetism ; and in this connexion it is necessary to assess more critically the real educational value of many 'visual aids'.

It remains to be said that in spite of the very worthy production of the book, the half-tone illustrations with which it is illustrated have neither the size nor the quality desirable in a work of this type. Books on visual aids should set a good example.

W. L. SUMNER 